\title{
Transforming health professions education to advance toward universal health
}

Fernando Menezes da SILVA ${ }^{1}$

Jose Francisco García GUTIÉRREZ

\section{CONTEXT}

During the last biennium, several international organizations [1-3] formulated an ambitious road map to ensure an adequate health workforce worldwide that meets the present and future needs for the 2030 Agenda for Sustainable Development and its Goal 3 ("Ensure healthy lives and promote well-being for all at all ages") [4].

By 2030, an estimated 40 million additional health workers will be needed worldwide and there will likely be a gap of 18 million, which will affect middle- and low-income countries in particular [5]. Thus, governments have been urged to forge strong high-level intersectoral partnerships (health, education, work, and finances) to plan longterm development of human resources for health (HRH) and to increase public investment in health personnel as a strategy for inclusive economic growth, particularly for women and youth [3]. Requests have also been made to promote synergies to lessen imbalances among education of health professionals, requirements of health systems, and adequate responses to people's priority health needs [2-3].

Development of $\mathrm{HRH}$ in appropriate quantities and quality is an essential requirement to advance toward universal access to health and universal health coverage. Universal health will be only possible if $\mathrm{HRH}$ are available in sufficient numbers, equitably distributed, and have the appropriate capabilities for the needs of communities. Success in this regard is firmly associated with governance of public health policies, regulatory capacity, and the soundness of stakeholder accountability mechanisms for development and implementation of these processes [6].

As pointed out in the conclusions of the "Dublin
Declaration" (Fourth Global Forum on HRH 2017: Building the Health Workforce of the Future), the new health challenges of the 21st century are related to demographic, epidemiological, and technological changes that require personnel geared toward health promotion, disease prevention, people-centered community-based health services, and personalized long-term care [7].

In this regard, coordination between health systems and health professions education institutions (HPEls) must be improved to align social commitment, education programs, required capacities, and available jobs with priority health needs, especially those of vulnerable and underserved populations.

\section{The necessary transformation of health professions education}

There is widespread agreement that $\mathrm{HRH}$ are the key component of health systems. Given that physicians, nurses, and other health professionals require many years of training, there is a need for projections that support public policies on the health workforce in the mid- and long-term. However, the separation between the health and education sectors, as well as the lack of multisectoral collaboration for financing, planning, and evaluation, continues producing HRH systems that are fragmented, inefficient, and expensive in many countries.

Furthermore, it is increasingly being recognized that current educational models are inadequate to respond comprehensively to labor market and health system requirements and to the needs of the population. These problems are systemic: mismatch of competencies to patient and population needs; poor teamwork; persistent gender stratification of professional status in contrast to the feminization of the work force; narrow technical

\footnotetext{
${ }^{1}$ Pan American Health Organization/World Health Organization. Department of Health Systems and Services. 525 23rd Street, NW, Washington, DC 20037, EUA. Correspondence to: FM SILVA. E-MAIL: <menezesf@paho.org>.

$\mathbf{v} \mathbf{v}$

Como citar este artigo / How to cite this article

Da Silva, Fernando Menezes. Transforming health professions education to advance toward universal health. InterAm J Med Health. 2018;1:e201801006.
} 
focus with difficulties in addressing social determinants of health; episodic encounters rather than continuous care; predominant hospital orientation at the expense of primary care; quantitative and qualitative imbalances in the professional labor market; and weak leadership to improve health-system performance [8].

Despite this panorama, health professions education continues to be predominantly focused on the traditional biomedical model, using fragmented, obsolete, and static curricula, and favoring hospital overspecialization. Fortunately, evidence is emerging that the transformation to socially committed education (which seeks to ensure that educational programs are relevant to the local context and that needs are detected in partnership with communities) serves to strengthen health services and positively influence the availability, distribution, quality, and performance of the HRH that are needed [9].

\section{Social accountability of health sciences education: a growing option}

The World Health Organization (WHO) has defined social accountability $\left({ }^{*}\right)$ of HPEls as: "The obligation to direct their education, research, and service activities towards addressing the priority health concerns of the community, region, and/or nation they have a mandate to serve [10].

(*) Authors' Note: The term "social accountability" refers to the definition by Boelen \& Heck 1995, (10) which involves the highest degree of "social obligation." This requires monitoring the impact of the performance of graduates on the community, access to health services, and improvements in population health status, all aligned with the basic principles of quality, equity, relevance, and cost-effectiveness.

Although there are differences in the interpretation and implementation of this definition, the interventions most commonly used at present to put the concept of social accountability into practice include: a) alignment of the curricula with local needs; b) prioritizing recruitment of students from underserved communities; c) early exposure to primary care; d) residency and graduate-level training in disadvantaged areas; e) interprofessional education and practice; and f) active participation of communities and other stakeholders [Table 1]

HPEls that aspire to be socially accountable have to carry out the same activities as traditional academic institutions (education, research, and service), but distinguish themselves because their mission is focused on priority health needs in their own contexts. This frequently means underserved populations that have difficulty accessing health services: remote, rural, and urban fringe communities; indigenous or minority groups; and ethnic and linguistically diverse communities.

Table 1. The ten main strategies implemented by academic institutions that aspire to excellence in the education of socially accountable health professionals.

1. Education, research, and service programs are designed to meet the health and social needs of the communities that the institution has the mandate to serve, and which are identified in partnership with communities and other stakeholders.

2. Students are recruited from the communities with the greatest health needs or from those that are considered to be the most willing to work in neglected areas.

3. Programs are located within or in close proximity to the communities the institution serves.

4. Much of the learning takes place in settings where graduates are expected to work (in communities and in the first level of care) instead of in university classrooms and tertiary hospitals.

5. The curriculum integrates basic and clinical sciences with population health needs, social sciences, social determinants of health, and public health. Early contact with patients and community services increases the relevance and value of theoretical learning.

6. Pedagogical methodologies are student centered (including service-based training), strengthen interprofessional teamwork, and are assisted by information communication technology.

7. Community-based practitioners are recruited and trained as teachers and mentors.

8. Programs and faculty model commitment to public health services.

9. Social accountability is reflected in all departments and in commitment from the leadership.

10. Institutions partner with the health system to produce locallyrelevant competencies and evaluate the impact of strategies on population health.

Adapted from Ross et al., 2014 (11)

In this context, the inclusion of social accountability in accreditation processes could be instrumental to improving availability of health professionals aligned with social needs. Accreditation could help broaden the social scope of the health system if it includes criteria for equity, relevance, and effectiveness, as well as indicators to measure the capacities of graduates and the production of research relevant to meeting the health needs of the population. Other examples could be social equality in admissions; scholarships for students from ethnic minorities and disadvantaged communities; a degree of curriculum exposure to work in primary care; and criteria for adaptation, such as encouraging graduates to begin their service in underserved areas [12]. 
There is an urgent need to introduce accreditation standards and regulations that reflect social accountability in health sciences education. Only then can HPEls be measured and rewarded for their real capacity to meet the pressing health needs of society and contribute to attaining universal health for everyone, everywhere.

\section{Some notes on Latin America}

During the last decades, HPEls in Latin America have grown exponentially and haphazardly. In many countries, regulation and accreditation processes have been inefficient and there are concerns about the quality of education, relevance of academic programs, and graduates' capacity for professional practice. There are also difficulties in moving forward with skills-based training, establishing interprofessional learning programs, designing flexible curricula, strengthening teaching capacity, and diversifying learning contexts. Notwithstanding, more and more HPEls are redefining their social responsibilities and developing professional profiles consistent with the health needs of the communities they serve [2].

The following actions have recently been proposed for HPEI social accountability to continue to develop in the countries of our Region [13]:

1. Develop an instrument that enables assessing the level of progress and development of social accountability in the Region's HPEls.

2. Conduct studies on the interpretation of social accountability, incorporating the perspectives of academic authorities, students, faculty, heads of health services, social agents, and end beneficiaries (e.g., general population, vulnerable groups, users of health services, and patients with certain clinical problems).

3. Establish a regional network of HPEls that work in partnership to advance together on social accountability issues.

4. Promote the inclusion of social accountability criteria and indicators in HPEl accreditation standards, both at the national level and regionally and internationally.

These actions will also help to facilitate universal access to quality health services and to serve the health needs of populations.

\section{REFERENCES}

1. World Health Organization. Global strategy on human resources for health: workforce 2030. Geneva: WHO; 2016.

2. Pan American Health Organization. CSP29/10. Strategy on Human Resources for Universal Access to Health and Universal
Health Coverage. 29th Pan American Sanitary Conference, 69th Session of the Regional Committee of WHO for the Americas; 25-29 September 2017; Washington, DC: PAHO; 2017.

3. United Nations High-Level Commission on Health Employment and Economic Growth. Health Employment and Economic Growth: A Five-Year Action Plan (2017-2021) Geneva, Switzerland. International Labour Organization, Organisation for Economic Co-operation and Development, World Health Organization; 2017.

4. United Nations. General Assembly. Resolution A/RES/70/1. Transforming our world: the 2030 Agenda for Sustainable Development. New York: United Nations; 2015.

5. Liu JX, Goryakin Y, Maeda A, Bruckner T, Scheffler R. Global health workforce labor market projections for 2030. Hum Resour Health. 2017;15(1):11. doi: 10.1186/s12960-017-01872

6. Pan American Health Organization. CD53/5, Rev. 2. Strategy on Human Resources for Universal Access to Health and Universal Health Coverage [Internet]. 53rd PAHO Directing Council, 66th Session of the Regional Committee of WHO for the Americas; 29 September-3 October 2014; Washington, DC: PAHO; 2014.

7. World Health Organization. Dublin Declaration on Human Resources for Health: Building the Health Workforce of the Future. Fourth Global Forum on Human Resources for Health. Dublin, Ireland, 13-17 November 2017.

8. Frenk J, Chen L, Bhutta ZA, Cohen J, Crisp N, Evans T, et al. Health professionals for a new century: transforming education to strengthen health systems in an interdependent world. Lancet. 2010;376(9756):1923-58. doi: 10.1016/S01406736(10)61854-5

9. Kaufman A, Roth PB, Larson RS, Ridenour N, Welage LS Romero-Leggott $V$, et al. Vision 2020 measures University of New Mexico's success by health of its state. Am J Prev Med. 2015 Jan;48(1):108-15. doi: 10.1016/j.amepre.2014.08.001

10. Boelen C, Heck J. Defining and measuring the social accountability of medical schools. Geneva: World Health Organization; 1995.

11. Ross S, Preston R, Lindemann I, Matte M, Samson R, Tandinco $\mathrm{F}$, et al. The training for health equity network evaluation framework: A pilot study at five health professional schools. Educ Health. 2014;27:116-126. doi: 10.4103/1357-6283.143727. doi: 10.4103/1357-6283.143727

12. Boelen C, Woollard R. Social accountability and accreditation: a new frontier for educational institutions. Med Educ 2009;43(9):887-894. doi: 10.1111/j.1365-2923.2009.03413.x

13. Püschel K, Riquelme $A$, Moore $P$, et al. What makes a medical school socially accountable in Latin America? A report from a Latin American panel based on a qualitative approach. Medical Teacher. 2017. doi: 10.1080/0142159X.2017.1296119. 